Tropical Journal of Pharmaceutical Research November 2015; 14 (11): 2061-2069

ISSN: $1596-5996$ (print); 1596-9827 (electronic)

(c) Pharmacotherapy Group, Faculty of Pharmacy, University of Benin, Benin City, 300001 Nigeria.

All rights reserved.

Available online at http://www.tjpr.org

Original Research Article

http://dx.doi.org/10.4314/tjpr.v14i11.16

\title{
In vitro Evaluation of Trimethoprim and Sulfamethoxazole from Fixed-Dose Combination Generic Drugs using Spectrophotometry: Comparison of Flow-Through Cell and USP Paddle Methods
}

\author{
Raúl Medina ${ }^{1 \star}$, Maximiliano Miranda ${ }^{1}$, Marcela Hurtado ${ }^{1}$, Adriana M Domínguez- \\ Ramírez ${ }^{1}$, Octavio Reyes ${ }^{1}$ and Juan C Ruiz-Segura ${ }^{1,2}$ \\ ${ }^{1}$ Departamento de Sistemas Biológicos, UAM-Xochimilco Mexico, ${ }^{2}$ Departamento de Química Analítica, Fac. de Química \\ UNAM Mexico
}

*For correspondence: Email: rmlopez@correo.xoc.uam.mx

Received: 6 August 2014

Revised accepted: 3 September 2015

\begin{abstract}
Purpose: To develop a first-order derivative spectrophotometric method for the determination of trimethoprim (TMP) and sulfamethoxazole (SMX) from fixed-dose combination generic products using a flow-through cell technique.

Methods: Absorbance measurement was achieved at 247.8 and $257.9 \mathrm{~nm}$ for trimethoprim and sulfamethoxazole, respectively. USP Apparatus 4 with $22.6 \mathrm{~mm}$ cells, laminar flow at $16 \mathrm{ml} / \mathrm{min}$, and 0.1 $\mathrm{N} \mathrm{HCl}$ at $37{ }^{\circ} \mathrm{C}$ as dissolution medium, were used. Dissolution profiles were compared with modeldependent and independent methods.

Results: All the products met the pharmacopeial dissolution criterion ( $Q \geq 70 \%$, at $60 \mathrm{~min})$, except SMX in two products (SC $400 \mathrm{mg}$ and SB1 $800 \mathrm{mg}$ ) using the flow-through cell (53.62 and $49.74 \%$ dissolved, respectively). Using both USP apparatuses, significant differences in mean dissolution time and dissolution efficiency values were found $(p<0.05)$. All products were in line with Weibull's kinetics and significant differences in derived parameters $(T d)$ values were found $(p<0.05)$.

Conclusion: Determination of TMP and SMX by derivative spectrophotometry can easily be employed for dissolution studies using the flow-through cell technique. However, it would be necessary to determine correlation with in-vivo test results in order to assure safe interchangeability.
\end{abstract}

Keywords: Trimethoprim, Sulfamethoxazole, Flow-through cell method, First-order derivative spectrophotometry, Fixed-dose combination generic drugs

Tropical Journal of Pharmaceutical Research is indexed by Science Citation Index (SciSearch), Scopus, International Pharmaceutical Abstract, Chemical Abstracts, Embase, Index Copernicus, EBSCO, African Index Medicus, JournalSeek, Journal Citation Reports/Science Edition, Directory of Open Access Journals (DOAJ), African Journal Online, Bioline International, Open-J-Gate and Pharmacy Abstracts

\section{INTRODUCTION}

Recently, several authors have been worried about safe interchangeability between branded products and its generic counterpart or even among different generic products. For several drugs, interesting and different results have been reported [1,2]. Importance of in-vitro dissolution test to guarantee a best quality in generic medications is widely discussed by regulatory organisms [3]. According to FDA and WHO guidelines, some generic drugs can be registered on the basis of only in-vitro data (dissolution test) without testing their in-vivo performance [4]. In Mexico, as in other parts of the world, trimethoprim-sulfamethoxazol (TMP-SMX) immediate-release oral fixed-dosage forms are marketed as generic drugs. The combination is 
prepared in different formulations but tablets are the most commonly used, mainly for the advantages of patient management and intake of a solid dosage form.

TMP-SMX inhibits bacterial synthesis of tetrahydrofolic acid, the physiologically active form of folic acid and a necessary cofactor in the synthesis of thymidine, purines and bacterial DNA. The fixed 1:5 formulation of TMP-SMX is indicated primarily for treating genitourinary, gastrointestinal, and respiratory tract infections as well as skin-associated infections and HIVinfected patients [5]. Development of bacterial resistance and adverse reactions are well documented [6].

According to Biopharmaceutical Classification System, TMP and SMX are classified as Class II drugs [7]. Due to their low aqueous solubility, dissolution rate is the rate-limiting step for absorption. TMP and SMX are well absorbed after oral administration however; TMP is absorbed more rapidly than SMX and is more widely distributed throughout the body. Because of this unequal distribution, a widely range of concentrations is achieved in different tissues and body fluids [6]. Furthermore, in-vitro dissolution data offer the best method to predict in-vivo performance formulation. In this regard, some authors have been documented differences in in-vitro release characteristics of TMP-SMX commercial products [8].

Spectrophotometric approaches for simultaneous analysis of binary and ternary mixtures in commercial tablets were previously reported $[9,10]$. Studies are often focused on in-vitro dissolution profiles of TMP-SMX without previous extraction steps and interference of matrix effect; however, alkaline or a combination of alkaline/methanolic solutions are usually used in those studies but pharmacopeial dissolution method is carried out in acidic medium $(0.1 \mathrm{~N}$ $\mathrm{HCl})$. Other kinds of solutions are not the natural environment where drugs will be dissolved within the first minutes after tablets intake. Dissolution profiles of TMP-SMX commercial products with derivative spectrophotometry were also reported. The aid of some devices and continuous-flow methodology knowing as multi-commutation is included [11]. For pharmaceutical analysis of TMP-SMX brand products, automated dissolution systems fitted with an integrated multicomponent detector was reported [8]. Determination of multicomponent dissolution profiles of TMP-SMX pharmaceutical products by in-situ fiber-optic UV measurements was also described [12]. For current pharmaceutical laboratories these equipments are not easily available and routine dissolution profiles comparisons with binary mixtures is difficult to carry out.

For the evaluation of dissolution profiles of TMPSMX tablets, the United States Pharmacopeia (USP) [13] specifies the use of USP paddle method at $75 \mathrm{rpm}$ with $900 \mathrm{ml}$ of $0.1 \mathrm{~N} \mathrm{HCl}$ as dissolution medium and not less than $70 \%(\mathrm{Q})$ of TMP-SMX is dissolved in $60 \mathrm{~min}$. HPLC analysis for drugs quantification is recommended. An alternative to evaluate in-vitro drug release is the flow-through cell system (USP Apparatus 4). Its advantages over the conventional basket and paddle methods (USP Apparatus 1 and 2, respectively) are widely demonstrated, especially for the dissolution of poorly soluble drugs $[14,15]$. The USP Apparatus 4 best simulates the hydrodynamic conditions that are found in the gastrointestinal tract. Therefore, it is important to investigate the applicability of the flow-through cell system on the assessment of TMP-SMX dissolution profiles in order to ensure the adequate biopharmaceutical evaluation of fixeddose combination generic drugs.

The aim of this study was to apply a first-order derivative spectrophotometric method, especially developed for dissolution studies (USP paddle method), in the determination of dissolution profiles of TMP and SMX from fixed-dose combination generic drugs obtained with the flow-through cell system. Results were compared with data obtained with the pharmacopeial method, USP Apparatus 2.

\section{EXPERIMENTAL}

\section{Products and standard solutions}

Seven TMP-SMX immediate-release commercial products were used. Different letter was assigned to each one (A, B and C for $80 \mathrm{mg}$ of TMP and $400 \mathrm{mg}$ of SMX tablets) and (A1 and B1 for $160 \mathrm{mg}$ of TMP and $800 \mathrm{mg}$ of SMX tablets). Dissolution profiles of generic drugs were compared to dissolution profiles of the Mexican reference products ( $R$ and $R 1)$ Bactrim ${ }^{\circledR}$ and Bactrim $\AA$ F (Productos Roche, SA de CV, Mexico). Hydrochloric acid and methanol analytical grade were purchased from JT BakerMexico. TMP and SMX standards were purchased from Sigma-Aldrich Co. (St. Louis MO, USA). All samples were filtered through 0.45 $\mu \mathrm{m}$ nitrocellulose filters (Millipore ${ }^{\circledR}$, Ireland).

Standard solutions of both drugs were separately prepared by serial dilutions of the stock solutions 
of TMP $(0.2 \mathrm{mg} / \mathrm{ml})$ and SMX $(1 \mathrm{mg} / \mathrm{ml})$ in $0.1 \mathrm{~N}$ $\mathrm{HCl}$ to achieve the concentrations of $10-50$ $\mu \mathrm{g} / \mathrm{ml}$ of TMP and $250-350 \mu \mathrm{g} / \mathrm{ml}$ of SMX in the same medium.

\section{Content uniformity and assay}

Content uniformity and assay tests were performed with all products, according the procedures described in the USP [13].

\section{Analytical method validation}

The proposed analytical method was validated according to the International Conference on Harmonization (ICH) guidelines [16]. The system linearity, accuracy and precision were analyzed.

\section{Pharmacopeial dissolution method (USP Apparatus 2)}

TMP-SMX dissolution profiles were carried out according the procedures described in the USP [13]. An USP paddle apparatus (Sotax AT-7 Smart, Switzerland) with a piston pump (Sotax CY7-50, Switzerland) was used. Tablets were added on $900 \mathrm{ml}$ of $0.1 \mathrm{~N} \mathrm{HCl}$ at $37.0 \pm 0.5 \stackrel{\circ}{\circ}$ ( $\mathrm{n}$ $=6$ ). Rotational speed of $75 \mathrm{rpm}$ was tested. 10 $\mathrm{ml}$ of filtered samples were withdrawn at 15, 20, 30,45 , and 60 min and replaced with an equal volume of fresh dissolution medium to maintain a constant total volume.

\section{Flow-through cell method (USP Apparatus 4)}

TMP-SMX dissolution profiles were obtained with an automated flow-through cell system, USP Apparatus 4 (Sotax CE6, Sotax AG, Switzerland) with $22.6 \mathrm{~mm}$ cells (i.d.) and a piston pump (Sotax CY7-50, Sotax AG, Switzerland). In all experiments, laminar flow (with a bed of $6 \mathrm{~g}$ of glass beads) at $37.0 \pm 0.5^{\circ} \mathrm{C}$ was used. The degassed $0.1 \mathrm{~N} \mathrm{HCl}$ was used as the dissolution medium, at a flow rate of $16 \mathrm{ml} / \mathrm{min}$ and an open system was used. Dissolution samples were taken at 15, 20, 30, 45 and $60 \min (n=6)$.

\section{First-order derivative spectrophotometric analysis}

Simultaneous determination of TMP-SMX was carried out with a first-order derivative spectroscopic method previously developed in our laboratory [17]. A double beam UV/Vis spectrophotometer (Perkin Elmer Lambda 35, Waltham MA, USA) with $0.1 \mathrm{~cm}$ quartz cells was utilized. The operating conditions for UV analysis were first-derivative mode with scan speed 240 $\mathrm{nm} / \mathrm{min}$, slit width $2.0 \mathrm{~nm}$, and sampling interval $1.0 \mathrm{~nm}$. The amounts of TMP-SMX dissolved in both dissolution apparatuses were determined at 247.8 and $257.9 \mathrm{~nm}$ respectively, with reference to standard calibration curves.

\section{Data analysis}

TMP-SMX dissolution data of each product were used to calculate model-independent parameters: \% dissolved at $60 \mathrm{~min}(\mathrm{Q})$, mean dissolution time (MDT) [18] and dissolution efficiency (DE) [19]. The values of these parameters from generic drugs were compared with the reference products values by ANOVA followed by Dunnett's or Dunnett's T3 multiple comparisons test as appropriate. Data analysis was carried out using SPSS software (Version 17.0). Differences were considered significant if $p$ $<0.05$.

Additionally, in order to evaluate the release kinetics of TMP and SMX from the used products, dissolution data were fitted to different kinetic models: First order, Higuchi, KorsmeyerPeppas, Hixson-Crowell, Weibull and Logistic. The model with highest determination coefficient $\left(R^{2}\right.$ adjusted) and minimum Akaike Information Criterion (AIC) was chosen as the best fit [20]. Data analysis was carried out using Excel add-in DDSolver program [21]. To compare dissolution profiles with model-dependent methods a parameter derived from the best fit model was compared with an univariate one-way ANOVA followed by Dunnett's or Dunnett's T3 multiple comparisons test. Differences were considered significant if $p<0.05$.

\section{RESULTS}

\section{Pharmacopeial tests}

All products met the content uniformity and assay tests specified in the USP. The percentages of TMP-SMX on the content uniformity test ranged from $85-115 \%$ and the assay test was between 90 and $110 \%$, Table 1.

\section{Analytical method validation}

The mean regression equation from three standard calibration curves was $y=0.0349 x+$ 0.0124 for TMP and $y=-0.0100 x+0.2756$ for SMX. The relative standard deviation (RSD) values of response factor were 2.08 and $1.79 \%$ for TMP and SMX ranges, respectively. Considering dissolution of 80,100 and $120 \%$ of dose, the regression equation to assess the method linearity was $y=1.0005 x-0.0227$ for TMP and $y=1.0013 x+0.4559$ for SMX $\left(R^{2}=\right.$ $0.998 ; p<0.05)$. The method accuracy was 
Table 1: Mean content uniformity and assay results of trimethoprim (TMP) and sulfamethoxazole (SMX); $n=10$

\begin{tabular}{lcccc}
\hline Drug & Code & $\begin{array}{c}\text { Dose } \\
(\mathbf{m g})\end{array}$ & $\begin{array}{c}\text { Content } \\
\text { uniformity (min- } \\
\text { max) }\end{array}$ & Assay (\%) \\
\hline \multirow{3}{*}{ TMP } & TR & 80 & $99.17-101.03$ & 100.09 \\
& TA & 80 & $102.59-104.89$ & 103.77 \\
& TB & 80 & $103.50-106.24$ & 104.68 \\
SMX & TC & 80 & $100.72-103.22$ & 102.21 \\
& SR & 400 & $103.68-105.62$ & 104.65 \\
& SA & 400 & $98.38-100.58$ & 99.51 \\
TMP & SB & 400 & $99.01-101.63$ & 100.13 \\
& SC & 400 & $101.97-104.50$ & 103.48 \\
\hline \multirow{3}{*}{ SMX } & TR1 & 160 & $100.84-103.00$ & 101.88 \\
& TA1 & 160 & $99.06-100.44$ & 99.95 \\
& TB1 & 160 & $101.48-103.83$ & 102.61 \\
\hline
\end{tabular}

$99.94 \%$ for TMP and $100.27 \%$ for SMX. The higher RSD value calculated to assess the method precision was $1.59 \%$. All commercial products met standard validation criteria too.

\section{Dissolution profiles}

TMP-SMX dissolution profiles obtained with the flow-through cell system and the USP paddle method are shown in Figure 1. Considering a single point specification ( $Q \geq 70 \%$ in $60 \mathrm{~min}$ ) all products met the pharmacopeial dissolution criterion in both USP apparatuses, excepting SMX in products SB (400 mg) and SB1 (800 mg) using USP Apparatus 4 (53.62 and 49.74\% dissolved, respectively). TMP-SMX dissolution test using the USP paddle method did not differentiate between the dissolution profiles; based on the pharmacopeial specifications all products tested reached the $Q$ value.

\section{Model-independent comparisons}

MDT and DE mean values \pm standard error for products under study in both USP apparatuses are shown in Table 2. Considering modelindependent comparisons significant differences in dissolution profiles of all generic drugs were found.

\section{Model-dependent comparisons}

In order to describe the TMP-SMX release kinetics from generic drugs, data were fitted to several kinetics models. Low values of $R^{2}$ adjusted and high values of AIC were found with almost all models. The dissolution data of all products in the flow-through cell system and the USP paddle method were best fitted by Weibull's function and the comparison of dissolution profiles was made analyzing the derived parameter (Td) from this function. Significant differences in $\mathrm{Td}$ values between generic drugs and the reference products were found $(p<0.05)$ in both USP apparatuses, Table 3.

\section{DISCUSSION}

First-derivative spectroscopic method was successfully applied for TMP-SMX determination together with the flow-through cell apparatus. In USP Apparatus 2 the UV analysis is also adequate because in both apparatuses, TMP and SMX achieved an extent of dissolution of $100 \pm 3 \%$ at $60 \mathrm{~min}$ from the reference products. In all sampling times the RSD was lower than 3 $\%$. Results in USP Apparatus 4 showed a slower dissolution rate than the one found with the USP paddle method. This behavior can be explained by the hydrodynamic conditions that characterize the flow-through cell, where no agitation mechanisms exists and the dosage form and the drug particles are continuously exposed to a uniform laminar flow, similar to the natural environment of the gastrointestinal tract, causing different in-vitro dissolution pattern [22]. Invitro/in-vivo correlation (IVIVC) using the flowthrough cell at flow rates of 8,16 and $32 \mathrm{ml} / \mathrm{min}$ has been previously discussed [23] as well as flow rates of 4,8 and $16 \mathrm{ml} / \mathrm{min}$ are also in the European Pharmacopeia and the USP.

The analytical method validation was done with all products used in the present study however, as an example and in order that method validation is not the main objective of this work, only the reference product $\mathrm{R}$ (80/400 mg-dose) data are shown. 
USP Paddle method
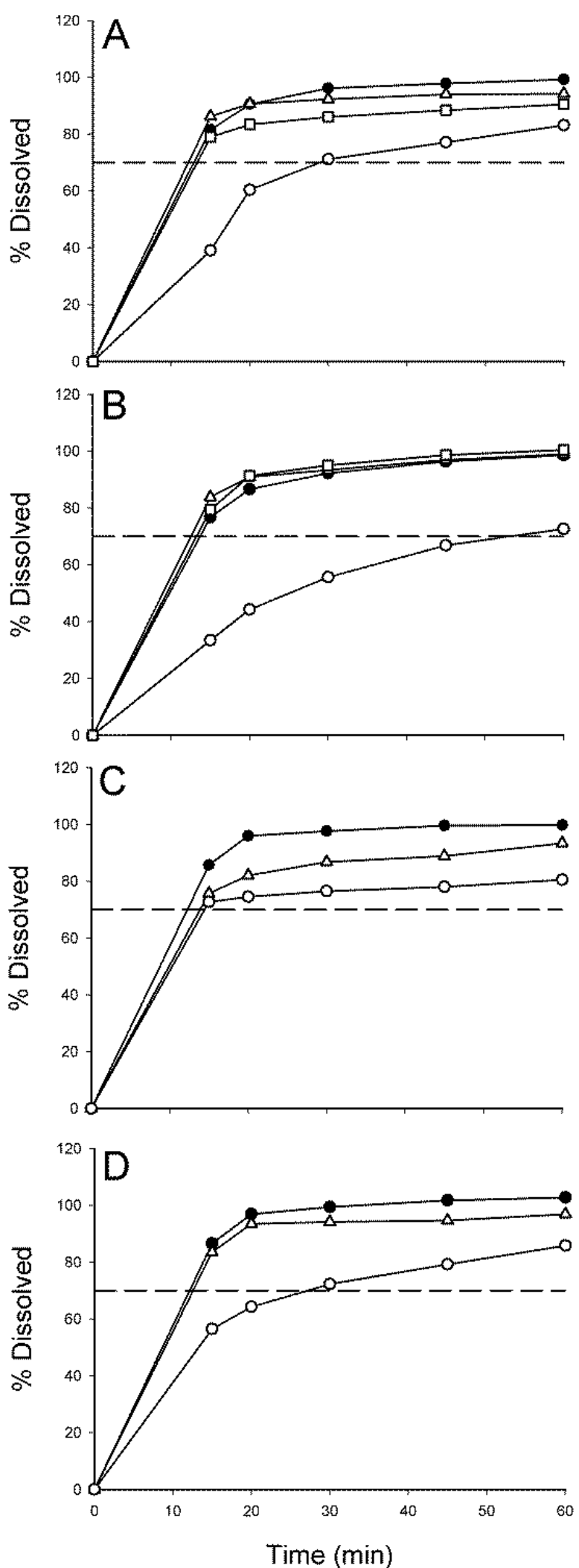

Flow-through cell
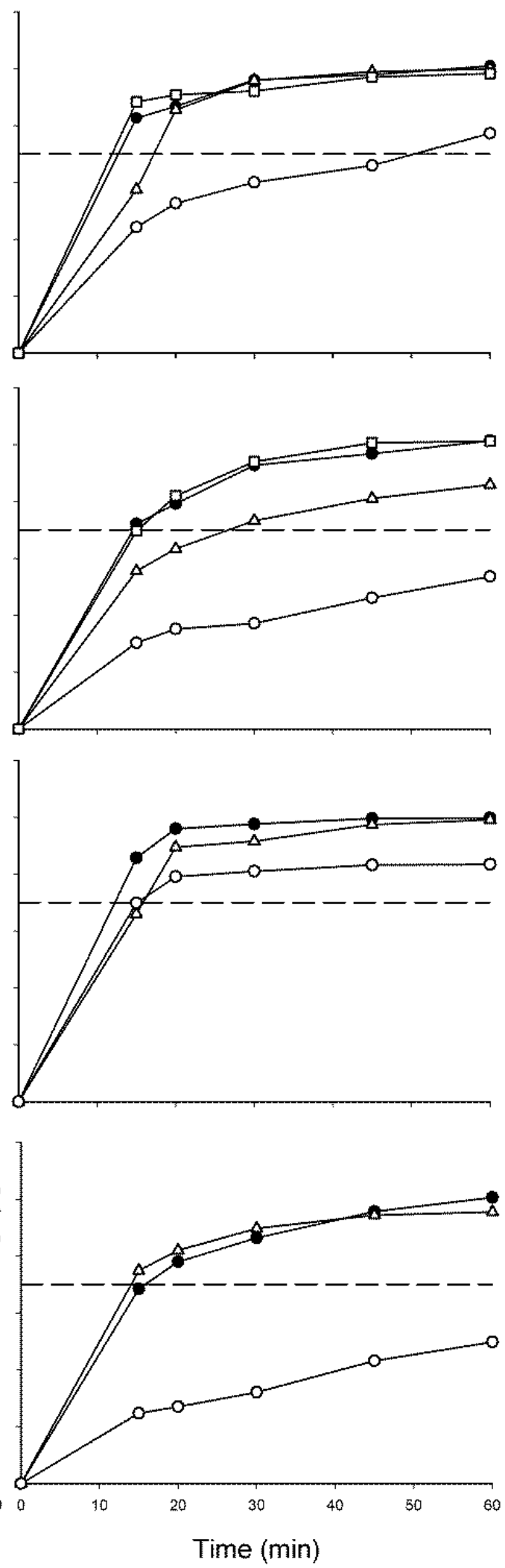

Figure 1: Dissolution profiles of trimethoprim-sulfamethoxazole from fixed-dose combination reference and generic products (Key: A) • TR, $\Delta \mathrm{TA}, \circ \mathrm{TB}$ and $\square \mathrm{TC}$. B) $\bullet \mathrm{SR}, \Delta \mathrm{SA}, \circ \mathrm{SB}$ and $\square \mathrm{SC}$. C) $\bullet$ TR1, $\triangle \mathrm{TA} 1$ and $\circ$ TB1. D) - SR1, $\triangle$ SA1 and $\circ$ SB1) evaluated with the USP paddle method and the flow-through cell system. Mean, $n=6$. Error bars were omitted for clarity 
Table 2: Model-independent parameters: percentage dissolved at $60 \mathrm{~min}$, mean dissolution time (MDT), and dissolution efficiency (DE) of trimethoprim (TMP) and sulfamethoxazole (SMX) from fixed-dose combination generic drugs. Data are mean $\pm \mathrm{SEM}, n=6:{ }^{*} p<0.05$

\begin{tabular}{|c|c|c|c|c|c|}
\hline Drug & Code & $\begin{array}{l}\text { Dose } \\
(\mathrm{mg})\end{array}$ & $\begin{array}{c}\% \text { Diss. } \\
\text { at } 60 \mathrm{~min}\end{array}$ & $\begin{array}{l}\text { MDT } \\
\text { (min) }\end{array}$ & $\begin{array}{l}\mathrm{DE} \\
(\%)\end{array}$ \\
\hline \multicolumn{6}{|c|}{ USP Paddle method } \\
\hline \multirow{4}{*}{ TMP } & TR & 80 & $99.28 \pm 0.45$ & $10.55 \pm 0.14$ & $81.81 \pm 0.21$ \\
\hline & TA & 80 & $94.24 \pm 0.58^{*}$ & $8.92 \pm 0.23^{*}$ & $80.22 \pm 0.44$ \\
\hline & $\mathrm{TB}$ & 80 & $83.13 \pm 0.96 *$ & $17.78 \pm 0.78^{*}$ & $58.53 \pm 1.56^{*}$ \\
\hline & $\mathrm{TC}$ & 80 & $90.53 \pm 0.73^{*}$ & $10.33 \pm 0.33$ & $74.94 \pm 0.77^{*}$ \\
\hline \multirow{4}{*}{ SMX } & SR & 400 & $98.63 \pm 0.26$ & $11.79 \pm 0.18$ & $79.25 \pm 0.18$ \\
\hline & SA & 400 & $98.95 \pm 0.15$ & $10.65 \pm 0.13^{*}$ & $81.39 \pm 0.21$ * \\
\hline & SB & 400 & $72.59 \pm 2.38^{*}$ & $19.93 \pm 0.41$ * & $48.46 \pm 1.54^{*}$ \\
\hline & SC & 400 & $100.44 \pm 0.46^{*}$ & $11.22 \pm 0.18$ & $81.65 \pm 0.27^{*}$ \\
\hline \multirow{3}{*}{ TMP } & TR1 & 160 & $99.74 \pm 0.23$ & $9.47 \pm 0.10$ & $83.99 \pm 0.12$ \\
\hline & TA1 & 160 & $93.39 \pm 1.73^{*}$ & $11.92 \pm 0.71$ * & $74.84 \pm 1.80$ * \\
\hline & TB1 & 160 & $80.50 \pm 0.33^{*}$ & $10.10 \pm 0.17$ & $66.94 \pm 0.14^{*}$ \\
\hline \multirow{3}{*}{ SMX } & SR1 & 800 & $102.77 \pm 0.39$ & $10.07 \pm 0.17$ & $85.52 \pm 0.14$ \\
\hline & SA1 & 800 & $96.87 \pm 0.46^{*}$ & $9.83 \pm 0.22$ & $81.00 \pm 0.23^{*}$ \\
\hline & SB1 & 800 & $85.81 \pm 0.20^{\star}$ & $15.92 \pm 0.12^{*}$ & $63.04 \pm 0.12^{*}$ \\
\hline \multicolumn{6}{|c|}{ Flow-through cell method } \\
\hline \multirow{4}{*}{ TMP } & TR & 80 & $100.96 \pm 0.48$ & $11.43 \pm 0.24$ & $81.72 \pm 0.40$ \\
\hline & TA & 80 & $99.95 \pm 1.01$ & $13.50 \pm 0.17^{*}$ & $77.46 \pm 0.58$ * \\
\hline & TB & 80 & $77.23 \pm 1.29^{*}$ & $19.12 \pm 0.58 *$ & $52.59 \pm 0.72^{*}$ \\
\hline & $\mathrm{TC}$ & 80 & $98.31 \pm 0.64$ & $10.06 \pm 0.10^{*}$ & $81.82 \pm 0.42$ \\
\hline \multirow{4}{*}{ SMX } & SR & 400 & $101.36 \pm 0.39$ & $13.76 \pm 0.19$ & $78.12 \pm 0.59$ \\
\hline & SA & 400 & $85.90 \pm 0.90^{*}$ & $15.67 \pm 0.37^{*}$ & $63.44 \pm 0.22^{*}$ \\
\hline & SB & 400 & $53.62 \pm 0.22^{*}$ & $20.40 \pm 0.10^{*}$ & $35.39 \pm 0.10$ * \\
\hline & SC & 400 & $101.22 \pm 0.42$ & $13.03 \pm 0.08^{*}$ & $79.24 \pm 0.37$ \\
\hline \multirow{3}{*}{ TMP } & TR1 & 160 & $100.88 \pm 0.52$ & $9.71 \pm 0.19$ & $84.54 \pm 0.20$ \\
\hline & TA1 & 160 & $99.13 \pm 0.39$ & $12.77 \pm 0.17^{*}$ & $78.02 \pm 0.17^{*}$ \\
\hline & TB1 & 160 & $83.47 \pm 0.74$ * & $9.93 \pm 0.16$ & $69.65 \pm 0.59^{*}$ \\
\hline \multirow{3}{*}{ SMX } & SR1 & 800 & $100.59 \pm 0.41$ & $14.89 \pm 0.09$ & $75.64 \pm 0.38$ \\
\hline & SA1 & 800 & $95.51 \pm 0.28^{*}$ & $11.65 \pm 0.23^{*}$ & $76.96 \pm 0.46$ \\
\hline & SB1 & 800 & $49.74 \pm 0.20^{*}$ & $22.38 \pm 0.02^{*}$ & $31.19 \pm 0.12^{*}$ \\
\hline
\end{tabular}

Results of the present study agree with those found by other authors where TMP from commercial tablets dissolved rapidly while SMX dissolved slowly [12,24]. For the study, USP Apparatus 2 at $75 \mathrm{rpm}$ was used. In another work, considering TMP-SMX generic drugs comparisons, dissolution profile of SMX from a commercially available product was slower than SMX profiles of other two evaluated products [8]. Authors used USP paddle method and $50 \mathrm{rpm}$ as agitation rate.

In order to compare the in-vitro dissolution data of TMP and SMX from fixed-dose combination generic drugs, model-independent parameters MDT and DE were calculated. These parameters have been proposed as adequate parameters for some IVIVC levels [25]. IVIVC Level B represents a relationship between MDT and the mean residence time, both calculated by statistical moments theory. IVIVC of oral TMPSMX formulations using data derived from statistical moments analysis was previously reported [26]. Three formulations gave $R^{2}$ of
0.99885 including both drugs in the same analysis. One of them was a commercially available product. On the other hand, Level C represents a single point correlation between one dissolution time point $\left(t_{50 \%}, t_{90 \%}\right.$, etc.) to one pharmacokinetic parameter such as AUC, $\mathrm{C}_{\max }$ or $T_{\max }$. DE was taken by some authors as a suitable parameter that expresses global drug dissolution performance useful for comparison of in-vitro dissolution profiles [19].

Comparison of dissolution profiles using modeldependent methods is a common methodology. Several authors reported adjustments of TMP. SMX dissolution profiles of commercially available formulations (tablets) to Higuchi's kinetic model. They suggested that Higuchi's equation allows an easy comparison of the parameters and curves and it fits better than polynomial equations [11]. However, results obtained in the present work adjusted to Weibull's kinetic model. This model has proven to be useful to describe in-vitro release kinetics of poorly soluble drugs in immediate-release oral dosage forms $[14,15]$. 
Table 3: Model-dependent parameters: $\alpha, \beta$ and Td values derived from the trimethoprim (TMP) and sulfamethoxazole (SMX) data adjusted to Weibull's kinetic model. Data are mean \pm SEM, $n=6:{ }^{*} p<0.05$

\begin{tabular}{|c|c|c|c|c|c|}
\hline Drug & Code & $\begin{array}{l}\text { Dose } \\
\text { (mg) }\end{array}$ & $\alpha$ & $\beta$ & $\begin{array}{c}T d \\
( \pm \text { SEM) }\end{array}$ \\
\hline \multicolumn{6}{|c|}{ USP Paddle method } \\
\hline \multirow{4}{*}{ TMP } & TR & 80 & 21.16 & 1.19 & $9.14 \pm 0.48$ \\
\hline & TA & 80 & 79.07 & 82.77 & $5.57 \pm 1.19^{*}$ \\
\hline & TB & 80 & 1987.27 & 1.90 & $17.92 \pm 0.64^{*}$ \\
\hline & $\mathrm{TC}$ & 80 & 84.95 & 84.83 & $5.66 \pm 0.60^{*}$ \\
\hline \multirow{4}{*}{ SMX } & SR & 400 & 8.76 & 0.92 & $9.24 \pm 0.59$ \\
\hline & SA & 400 & 4.13 & 0.67 & $5.66 \pm 0.90^{*}$ \\
\hline & SB & 400 & 44.48 & 1.15 & $24.83 \pm 1.86^{*}$ \\
\hline & SC & 400 & 55.31 & 1.28 & $9.81 \pm 0.70$ \\
\hline \multirow{3}{*}{ TMP } & TR1 & 160 & 132.06 & 1.87 & $10.15 \pm 0.47$ \\
\hline & TA1 & 160 & 423.84 & 34.22 & $8.02 \pm 0.85$ \\
\hline & TB1 & 160 & 1036.11 & 43.36 & $2.95 \pm 0.83^{*}$ \\
\hline \multirow{3}{*}{ SMX } & SR1 & 800 & 66.86 & 1.51 & $9.38 \pm 0.79$ \\
\hline & SA1 & 800 & 4979.41 & 2.17 & $10.04 \pm 0.92$ \\
\hline & SB1 & 800 & 126.62 & 7.79 & $19.73 \pm 2.03^{*}$ \\
\hline \multicolumn{6}{|c|}{ Flow-through cell method } \\
\hline \multirow{4}{*}{ TMP } & TR & 80 & 4.35 & 0.68 & $7.51 \pm 0.36$ \\
\hline & TA & 80 & 3319.53 & 2.88 & $15.67 \pm 0.11^{*}$ \\
\hline & TB & 80 & 9.59 & 0.71 & $24.20 \pm 1.84^{*}$ \\
\hline & $\mathrm{TC}$ & 80 & 1.17 & 0.25 & $1.91 \pm 0.18^{*}$ \\
\hline \multirow{4}{*}{ SMX } & SR & 400 & 9.25 & 0.87 & $12.43 \pm 0.25$ \\
\hline & SA & 400 & 1661.94 & 1.78 & $17.33 \pm 1.67$ \\
\hline & SB & 400 & 5870.83 & 1.71 & $82.50 \pm 0.62 *$ \\
\hline & SC & 400 & 22.75 & 1.19 & $13.28 \pm 0.13$ \\
\hline \multirow{3}{*}{ TMP } & TR1 & 160 & 3.73 & 0.57 & $3.66 \pm 1.16$ \\
\hline & TA1 & 160 & 3058.52 & 2.89 & $14.22 \pm 0.07^{*}$ \\
\hline & TB1 & 160 & 146.75 & 1.73 & $9.70 \pm 1.57^{*}$ \\
\hline \multirow{3}{*}{ SMX } & SR1 & 800 & 1514.87 & 1.26 & $14.49 \pm 0.16$ \\
\hline & SA1 & 800 & 1512.08 & 1.10 & $9.86 \pm 0.73^{*}$ \\
\hline & SB1 & 800 & 1967.28 & 1.55 & $86.22 \pm 0.54^{*}$ \\
\hline
\end{tabular}

The interchangeability of generic drugs is understood to mean the possibility for their mutual replacement in clinical practice while maintaining pharmacological response unaltered. The assessment of generics drugs interchangeability by in-vitro studies is one of the important task of the International Pharmaceutical Federation represented by the publication of "biowaiver monographs" [27]. Moreover, and with reference in the experience of a few countries, the role of generic medicines in healthcare systems and the need to establish and implement generic medicines policies is widely discussed by some authors [28]. Suitable in-vitro dissolution studies help to maintain an adequate quality control in formulations that may present potential bioequivalence problems.

\section{CONCLUSION}

First-order derivative spectroscopy is a useful technique for the simultaneous determination of TMP and SMX dissolution profiles from fixeddose combination generic drugs using the flowthrough cell method. The USP Apparatus 4 is effective in discriminating in-vitro dissolution characteristics of the different generic products.

\section{REFERENCES}

1. Ruiz ME, Gregorini A, Talevi A, Volonté MG. Dissolution studies of generic medications: new evidence of deviations from the transitivity principle. Dissol Technol 2012; 19(1): 13-24.

2. Al Ameri MN, Nayuni N, Anil Kumar KG, Perrett D. The differences between the branded and generic 
medicines using solid dosage forms: In-vitro dissolution testing. Results Pharma Sci 2012; 2: 1-8.

3. Anand $O, Y u L X$, Conner DP, Davit BM. Dissolution testing for generic drugs: an FDA perspective. AAPS J 2011; 13(3): 328-335.

4. Ramenskaya GV, Shokin IE. Modern approaches to quality evaluation of generic drugs for their registration (a review). Pharm Chem J 2009; 43(9): 512-515.

5. Masters PA, O'Bryan TA, Zurlo J, Miller DQ, Joshi $N$, Trimethoprim-sulfamethoxazole revisited. Arch Int Med 2003; 163: 402-410.

6. Kielhofner MA. Trimethoprim-sulfamethoxazole: pharmacokinetics, clinical uses, and adverse reactions. Tex Heart Inst J 1990; 17(2): 86-93.

7. Lindengerb $M$, Kopp $S$, Dressman JB. Classification of orally administered drugs on the World Health Organization Model list of Essential Medicines according to the biopharmaceutics classification system. Eur J Pharm Biopharm 2004; 58: 265-278.

8. Fuerte $V$, Maldonado $M$, Rees GD. The multicomponent automated dissolution system: an alternative in the development and pharmaceutical analysis of generic polydrugs. J Pharm Biomed Anal 1999; 21: 267-272.

9. Ribone MÉ, Pagani AP, Olivieri AC. Simultaneous multivariate spectrophotometric analysis of binary and ternary mixtures of sulfamethoxazole, trimethoprim and phenazopyridine in tablets. Anal Lett 1999; 32(7): 1389-1401.

10. Markopoulou CK, Malliou ET, Koundourellis JE. Chemometric and derivative methods as fexible spectrophotometric approaches for dissolution and assaying tests in multicomponent tablets. II Farmaco 2004; 59: 627-636.

11. Tomšů D, Catalá Icardo M, Martínez Calatayud J. Automated simultaneous triple dissolution profiles of two drugs, sulphamethoxazole-trimethoprim and hydrochlorothiazide-captopril in solid dosage forms by a multicommutation flow-assembly and derivative spectrophotometry. J Pharm Biomed Anal 2004; 36. 549-557.

12. Gemperline PJ, Cho J, Baker B, Batchelor B, Walker DS. Determination of multicomponent dissolution profiles of pharmaceutical products by in situ fiber-optic UV measurements. Anal Chim Acta 1997; 345: 155-159.

13. United States Pharmacopeia 30 National Formulary 24, United States Pharmacopeial Convention, Inc. Rockville, MD: 2007.

14. Hurtado M, Vargas Y, Domínguez-Ramírez AM, Cortés AR. Comparison of dissolution profiles for albendazole tablets using USP Apparatus 2 and 4. Drug Dev Ind Pharm 2003; 29: 777-784.

15. Medina JR, Salazar $D K$, Hurtado $M$, Cortés $A R$, Domínguez-Ramírez AM. Comparative in vitro dissolution study of carbamazepine immediaterelease products using the USP paddles method and the flow-through cell system. Saudi Pharm J 2014; 22: $141-147$.
16. International Conference on Harmonization, ICH Q2(R1). 2005. Validation of Analytical Procedures: Text and Methodology.

17. Medina JR, Miranda M, Hurtado M, Domínguez-Ramírez AM, Ruiz-Segura JC. Simultaneous determination of trimethoprim and sulfamethoxazole in immediaterelease oral dosage forms by first-order derivative spectroscopy: application to dissolution studies. Int $J$ Pharm Pharm Sci 2013; 5, (Suppl 4): 505-510.

18. Podczeck F. Comparison of in vitro dissolution profiles by calculating mean dissolution time (MDT) or mean residence time (MRT). Int J Pharm 1993; 97: 93-100.

19. Anderson NH, Bauer M, Boussac N, Khan-Malek R, Munden $P$, Sardaro $M$. An evaluation of fit factors and dissolution efficiency for the comparison of in vitro dissolution profiles. J Pharm Biomed Anal 1998; 17: 811-822.

20. Yuksel N, Kanik AE, Baykara T. Comparison of dissolution profiles by ANOVA-based, modeldependent and -independent methods. Int $J$ Pharm 2000; 209: 57-67.

21. Zhang Y, Huo M, Zhou J, Zou A, Li W, Yao C, Xie S. DDSolver: an add-in program for modeling and comparison of drug dissolution profiles. AAPS $J$ 2010; 12: 263-271.

22. Langenbucher F, Benz D, Kurth W, Moller H, Otz M. Standardized flow-cell method as an alternative to existing pharmacopoeial dissolution testing. Pharm Ind 1989; 51: 1276-1281.

23. Sunesen VH, Pedersen BL, Kristensen HG, Müller A. In vitro in vivo correlations for a poorly soluble drug, danazol, using the flow-through dissolution method with biorelevant dissolution media. Eur J Pharm Sci 2005; 24: 305-313.

24. Athanassiou GC, Rekkas DM, Choulis NH. Development of sulphamethoxazole-trimethoprim spheroidal granules: factors affecting drug release in vitro. Int $J$ Pharm 1991; 72: 141-147.

25. Demirtürk E, Öner L. In vitro-In vivo correlations. FABAD J Pharm Sci 2003; 28: 215-224.

26. Athanassiou GC, Rekkas DM, Choulis NH. Correlation of in vitro dissolution data with in vivo plasma concentrations, for three, orally administered, formulations of sulphamethoxazole-trimethoprim, by statistical moment analysis. Int J Pharm 1993; 90: 51-58.

27. Shokin IE, Ramenskaya GV, Vasulenko GF, Malalshenko EA. Assessment of the possibility of using comparative in vitro dissolution kinetics (biowaiver) instead of in vitro bioequivalence evaluation for establishing the interchangeability of generic drugs. Pharm Chem J 2011; 45(2): 107-109.

28. Hassali MA, Alrasheedy AA, McLachlan A, Nguyen TA, AL-Tamimi SK, Mohamed Ibrahim MI, Aljadhey $\mathrm{H}$. The experiences of implementing generic medicine policy in eight countries: $A$ review and recommendations for a successful promotion of

Trop J Pharm Res, November 2015; 14(11): 2068 
Medina et al

generic medicine use. Saudi Pharm J 2014. On line http://dx.doi.org/10.1016/j.jsps.2013.12.017 